\title{
PERBAIKAN WAKTU SETUP DENGAN MENGGUNAKAN METODE SMED PADA MESIN FILLING KRIM
}

\author{
Feby Nurhadiyanto Arief dan Zulfa Fitri Ikatrinasari \\ Program Studi Magister Teknik Industri, Universitas Mercubuana \\ e-mail: febyurhadiyantoarief@gmail.com
}

\begin{abstract}
ABSTRAK
PT. GP merupakan perusahaan farmasi yang memproduksi obat-obatan dalam bentuk sediaan padat, setengah padat dan cair. Perusahaan saat ini memproduksi krim/salep dengan hambatan lamanya waktu setup dan tingginya waktu stop selama proses yang mengakibatkan banyaknya overtime akibat penggunaan waktu kerja yang tidak efisien. Hal ini bertambah berat dengan variasi kemasan primer produk yang menuntut singkatnya waktu change over pada proses pengemasan primer. Permasalahan ini mendorong perusahaan untuk mengurangi waktu setup serta change over untuk mengatasi keterlambatan waktu penyelesaian. Tujuan penelitian ini untuk mendapatkan waktu setup dan change over yang lebih cepat pada mesin filling krim. Pengurangan waktu setup dan change over menggunakan salah satu metode lean manufacturing yaitu metode SMED. SMED (Single Minute Exchange of Dies) adalah salah satu metoda dalam lean production dalam mengurangi waste selama proses produksi. Metode SMED dapat dilakukan dengan memisahkan kegiatan setup menjadi dua tahap yaitu internal setup dan eksternal setup sehingga proses setup dan change over menjadi lebih efektif. Penerapan metode SMED pada penelitian ini menghasilkan penurunan waktu setup sebanyak $26 \%$ atau 16 menit
\end{abstract}

Kata kunci: Eksternal setup, Internal setup, metode SMED, Farmasi.

\begin{abstract}
PT. GP is a pharmaceutical company that produces drugs in solid, semi-solid and liquid dosage forms. The company currently produces creams / ointments with obstacles to set up time and high stop times during the process which results in a lot of overtime due to inefficient use of work time. This gets heavier with a variety of primary product packaging that requires a short time to change over the primary packaging process. This problem encourages companies to reduce setup time and change over to overcome delays in completion time. The purpose of this study is to get a faster setup and change over time on a cream filling machine. Reduction of setup and change over time using one of the lean manufacturing methods, namely the SMED method. SMED (Single Minute Exchange of Dies) is one method in lean production in reducing waste during the production process. The SMED method can be done by separating the setup activities into two stages: internal setup and external setup so that the setup and change over processes become more effective. The application of the SMED method in this study resulted in a decrease of $26 \%$ setup time or 16 minutes
\end{abstract}

Keywords: External Setup, Internal Setup, SMED Method, Pharmacy.

\section{PENDAHULUAN}

Perkembangan industri farmasi secara khusus dan dunia industri secara umum memaksa industri untuk menerapkan kaidahkaidah efisensi produksi. Produk-produk farmasi tidak lagi selalu produk yang bersifat mass production tetapi banyak yang kemudian mengalami kustomisasi menjadi produk yang lebih personal. Banyak perusahaan sekarang mempertimbangkan untuk beralih dari produksi massal ke kustomisasi massal. Kustomisasi massal adalah strategi untuk menawarkan produk dan jasa sesuai dengan keingingan individu dalam skala besar. Kustomisasi akan memberikan pelayanan yang lebih relevan terhadap keinginan dan kebutuhan pembeli dan membedakan penawaran dari pesaing, sehingga akan meningkatkan nilai penawaran [1].

Karena berbagai permintaan konsumen maka produk krim mengalami kustomisasi kemasan pada bagian pengemasan primer dan sekunder untuk memenuhi permintaan pasar. Hal ini mengakibatkan adanya proses change over dan perubahan penomoran lot selama proses produksi berlangsung yang menyebabkan perlunya perbaikan waktu setup dan change over yang efektif. Proses SMED atau adalah kunci dalam mengurangi besar volume lot dan akan mengurangi besar volume lot yang akhirnya akan meningkatkan flow 
proses produksi [2]. Banyak problem yang terjadi di lantai produksi seperti tingginya reject proses (44\%), tingginya over time (26\%), output proses di bawah standar (15\%). Perbaikan mesin yang tidak direncanakan (12\%), lain-lain (3\%).

Ada tiga alasan utama untuk pengurangan waktu setup. Pertama flexibilty, untuk dapat merespon dengan cepat terhadap perubahan permintaan pasar, fasilitas produksi harus bisa menghasilkan produk dengan variasi pada ukuran atau jenis dengan cara yang ekonomis. Kedua bottleneck capacity, mengurangi waktu setup meningkatkan kapasitas yang tersedia dan dapat di lihat sebagai cara alternatif bila dibandingkan dengan membeli peralatan baru. Ketiga reduce cost, terutama pada proses keterlambatan dan biaya produksi yang langsung berhubungan dengan kinerja mesin [3]. Diharapkan dengan penerapan SMED waktu setup dan change over dari proses kemas primer pada mesin filling krim dapat menjadi lebih cepat.

Dalam penelitian ini istilah waktu setup dan change over dibedakan untuk mengidentifikasi waktu penggunaanya secara mudah dimana istilah setup digunakan untuk proses setup pada saat awal proses sedangkan change over dilakukan ditengah proses produksi berlangsung. Tujuan penelitian ini adalah mendapatkan waktu setup dan change over yang lebih baik dengan metoda SMED (Single Minute Exhchange Dies). Proses set up adalah proses persiapan mesin dimana didalamnya ada proses pemasangan change part yang sesuai dan proses setting hingga menghasilkan produk yang sesuai standar. Waktu setup adalah suatu proses perubahan dari suatu produk ke produk lainya pada suatu mesin atau deretan mesin yang berhubungan dengan merubah suku cadang, cetakan atau fungsi lainnnya [4]. Waktu change over dihitung dari waktu produk yang baik di hasilkan hingga produk baru yang dihasilkan dari suatu mesin setelah proses change over [5].

\section{METODOLOGI PENELITIAN}

Kata single minute dalam singkatan SMED tidak berarti merubah waktu setup hanya satu menit akan tetapi menjadikannya digit tunggal sehingga diartikan bahwa setup harus diusahakan di bawah 10 menit [6]. Waktu set up pada kasus ini mengambil bagian cukup besar dari total waktu penyelesaian proses pengemasan primer bulk krim. Dampak dari lamanya dari waktu setup ini berupa menimbulkan bahaya kerusakan bulk krim akibat terlalu lama terpapar panas dalam hopper selama proses pengemasan primer . Untuk melihat bagaimana keadaan di ruang produksi dan bagaimana cara melakukan perbaikan diperlukan suatu pendekatan sistematis yang diperlukan. Lean manufacture merupakan suatu pendekatan sistematis yang digunakan untuk mengidentifikasi dan mengeliminasi pemborosan (waste) melalui aktivitas perbaikan secara terus menerus. Penelitian-penelitian mengenai cara memperbaiki waktu setup dan mengurangi waktu menunggu telah banyak diterapkan, antara lain dengan menggunakan metode SMED dan Standardization Work. Dalam penerapan lean manufacturing metoda ini tidak hanya akan berdiri sendiri tetapi berjalan sinergi dengan metode-metode lain dalam lean manufacturing. Tahapan yang dilakukan untuk menerapkan SMED adalah [7][8]:

\section{Pendahuluan.}

Melakukan beberapa pendekatan untuk menyatakan kondisi nyata dari sistem produksi yang ada, dengan cara melakukan wawancara dengan pekerja untuk mengetahui tahapan proses setup, mendokumentasikan proses kerja yang dilakukan oleh operator mesin, tidak membedakan antara internal dan eksternal setup, menganalisis proses setup menggunakan stopwatch dan proses produksi.

Langkah pertama

Memisahkan internal setup dan eksternal set up. Internal setup merupakan proses set up pada saat mesin berhenti beroperasi, sedangkan eksternal setup merupakan proses setup saat mesin sedang dalam proses beroperasi. Gunakan checklist untuk semua komponen dari setiap langkah dalam proses produksi.

\section{Langkah kedua}

Mengubah internal setup menjadi eksternal setup. Cara mengubah internal setup menjadi eksternal setup sebagai berikut: lakukan langkah pemeriksaan kembali pada 
setiap operasi untuk melihat apakah ada langkah yang salah sehingga diasumsikan sebagai internal setup dan temukan cara untuk mengubah langkah tersebut menjadi eksternal setup.

\section{Langkah ketiga}

Merampingan semua aspek proses, dengan cara melakukan perbaikan internal setup dengan cara perbaikan berkelanjutan dengan tujuan untuk meminimalkan waktu setup internal sehingga waktu berhenti mesin dapat dikurangi.

\section{HASIL DAN PEMBAHASAN \\ Proses Produksi Krim}

Proses produksi dilakukan melalui 2 tahap yaitu: proses pembuatan bulk krim dan proses pengemasan. Setelah proses pembuatan bulk krim, bulk krim disimpan dalam WIP dan menunggu proses analisa Quality Control Departement. Setelah mendapatkan status release produk maka bulk disiapkan untuk proses pengemasan. Proses pengemasan di bagi menjadi dua bagian yaitu: pengemasan primer yang dilakukan di ruang kelas $\mathrm{E}$ (ruang produksi) dimana bulk dimasukkan ke dalam tube alumunium dengan ukuran 5 gram, 10 gram dan 15 gram tergantung kebutuhan konsumen. Pengemasan primer dilakukan dengan mesin filling krim. Proses pengemasan primer ini yang akan dilakukan optimasi waktu setup melalui metode SMED. Pengemasan sekunder dilakukan di ruang kelas $\mathrm{F}$ (ruang pengemasan) dimana tube alumunium yang telah berisi krim dimasukkan ke dalam box karton dan dikemas untuk didistribusikan ke konsumen. Pengemasan Sekunder dilakukan secara manual menggunakan tenaga manusia.

\section{Kegiatan Setup Sebelum Penerapan Metode SMED}

Pada proses pengemasan primer bulk krim yang telah siap dilakukan proses pengemasan primer di masukkan ke dalam hopper dan kemudian kemasan primer berupa tube 5 gram, 10 gram atau 15 gram diletakkan secara manual menggunakan tangan ke dalam tube holder yang berada pada rotary pan untuk kemudian tube alumunium diisi bulk krim oleh dosing pump hingga seluruh bulk krim di dalam hopper bulk habis.

Berikut kegiatan setup sebelum penerapan SMED di mesin filling krim sebelum dilakukan penyederhanaan dari kegiatan internal setup menjadi exsternal setup proses. Kegiatan tersebut secara garis besar adalah:

Persiapan proses, proses ini mencakup dokumentasi produk, label release produk, dokumentasi mesin ruang dan operator

Setup tube holder, melepas tube holder, kemudian memasang kembali dies dengan ukuran yang sesuai.

Setup filling rig adalah bagian mesin yang melakukan proses sealing mekanik (mekanisme cramping) pada tube alumunium setelah bulk krim dimasukkan ke dalam tube alumunium oleh dosing pump.

Setup dosing pump melakukan proses pengisian bulk ke dalam tube alumunium sesuai dengan ukuran bobot yang diinginkan.

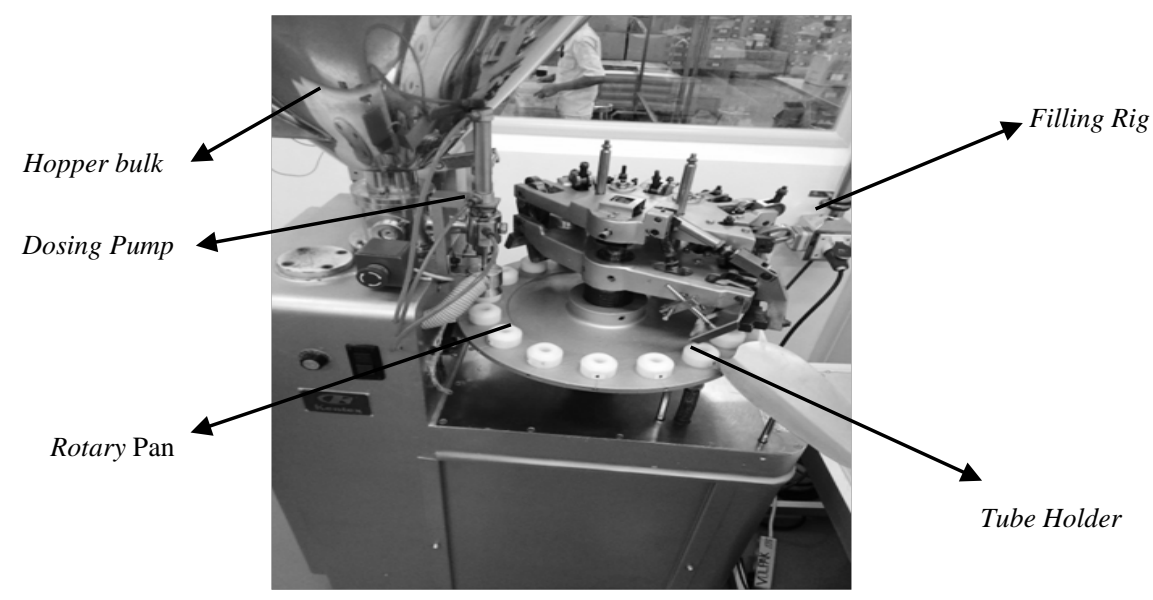

Gambar 1. Mesin Filling Krim 
Tabel 1. Proses Setup Sebelum Penerapan Proses SMED

\begin{tabular}{clccc}
\hline $\begin{array}{c}\text { Langkah } \\
\text { ke- }\end{array}$ & \multicolumn{1}{c}{ Proses } & $\begin{array}{c}\text { Internal/ } \\
\text { eksternal }\end{array}$ & $\begin{array}{c}\text { Waktu } \\
\text { (menit) }\end{array}$ & Pelaksana \\
\hline 1 & Menyiapkan tools, p10, p5, ku L, T 10 & Internal & 2 & Operator \\
2 & Memasang hopper bulk & Internal & 7 & Operator \\
3 & Mengisi bulk ke hopper bulk & internal & 15 & Operator \\
4 & Membuka tube holder pada rotary pan & Internal & 4 & Operator \\
5 & Memilih tube holder & Internal & 1 & Operator \\
6 & Memasang tube holder & Internal & 5 & Operator \\
7 & Mengatur ketinggian filling rig & Internal & 5 & Operator \\
8 & Melakukan adjustment cramping & Internal & 10 & Operator \\
9 & Menyiapkan nomor batch & Internal & 3 & Operator \\
10 & Memasang nomor batch pada stamp & Internal & 3 & Operator \\
11 & Memasang stamp batch pada filling rig & Internal & 3 & Operator \\
12 & Melakukan pengaturan dosing & Internal & 3 & Operator \\
\hline \multicolumn{7}{c}{ Total } & & 61 & \\
\hline
\end{tabular}

Tabel 2. Small Stops Selama Proses Pengemasan Primer

\begin{tabular}{cllcc}
\hline $\begin{array}{c}\text { Stop } \\
\text { ke - }\end{array}$ & \multicolumn{1}{c}{ Proses } & \multicolumn{1}{c}{ Penyebab } & $\begin{array}{c}\text { Waktu } \\
\text { (menit) }\end{array}$ & Pelaksana \\
\hline 1 & Melakukan pengaturan dosing & Bobot isi lebih & 0,5 & Operator \\
2 & Melakukan adjustment cramping & Lipatan cramping & 3 & Operator \\
3 & Penggantian tube holder & Tube holder tidak pas & 2 & Operator \\
4 & Melakukan pengaturan dosing & Bobot isi kurang & 1 & Operator \\
5 & Penggantian tube holder & Tube holder tidak pas & 1 & Operator \\
6 & Melakukan adjustment cramping & Lipatan cramping & 3 & Operator \\
7 & Penggantian tube holder & Tube holder tidak pas & 1 & Operator \\
8 & Mengisi bulk ke hopper bulk & Bulk lot ke dua & 15 & Operator \\
9 & Change over 10 gram & Ganti kemasan primer & 39 & Operator \\
10 & Melakukan adjustment cramping & Lipatan cramping & 3 & Operator \\
11 & Melakukan pengaturan dosing & Bobot isi lebih & 0,5 & Operator \\
12 & Penggantian tube holder & Tube holder tidak pas & 1 & Operator \\
13 & Melakukan adjustment cramping & Lipatan cramping & 3 & Operator \\
14 & Penggantian tube holder & Tube holder tidak pas & 1 & Operator \\
15 & Melakukan pengaturan dosing pump & Bobot isi kurang & 1 & Operator \\
\hline \multicolumn{7}{c}{ Total } & & 75 & \\
\hline
\end{tabular}

Langkah kerja tersebut kemudian diamati tanpa membedakan apakah internal atau eksternal setup, lalu diukur waktu yang digunakan, seperti pada Tabel 1.

Dari hasil pengamatan pertama terjadi 1 kali change over dan 15 kali stop selama 6 jam operasional mesin dengan reject 211 (4400) tube 5 gram dan 127 (2200) tube 10 gram dalam total waktu operasional mesin. Untuk proses change over semua langkah di atas dilakukan kembali kecuali langkah ke-2 dan ke-3 karena pada langkah ke-2 hopper bulk telah terpasang dan pada langkah ke-3 bulk krim belum tentu ditambahkan. Proses terhentinya mesin dicatat dan didokumentasikan penyebab dan lamanya seperti terlihat pada Tabel 2.

Bila dikalkulasikan secara seksama maka dari total operasional mesin selama 6 jam dari setup hingga proses pengemasan primer selesai hanya sekitar 62\% (136/360) yang digunakan untuk proses pengemasan primer 224 menit dan sisanya 136 menit digunakan untuk proses setup dan change over dan small stop. Berikut Tabel penyebab dari small stop selama proses pengemasan primer tersebut.

Tabel 3. Pareto Penyebab Stop

\begin{tabular}{clcc}
\hline No. & \multicolumn{1}{c}{ Penyebab Stop } & Jumlah & $\%$ \\
\hline 1 & $\begin{array}{l}\text { Melakukan pengaturan } \\
\text { dosing pump } \\
2\end{array}$ & 4 & 26 \\
$\begin{array}{l}\text { Melakukan adjustment } \\
\text { cramping }\end{array}$ & 4 & 26 \\
3 & $\begin{array}{l}\text { Penggantian tube holder } \\
4\end{array}$ & 5 & 33 \\
\hline$\quad$ Proses change over dan bulk & 2 & 13 \\
\hline & Total & 15 & 100 \\
\hline
\end{tabular}




\section{Kegiatan Setup Setelah Penerapan Metode SMED}

Pada tahap ini dilakukan brainstorming dan identifikasi proses apa saja yang bisa di jadikan proses eksternal dan juga didiskusikan penyebab dari banyaknya small stop serta tidak adanya dokumentasi yang menyertainya. Pada kesempatan berikutnya proses setup diulang dengan tambahan 1 orang asisten operator yang melakukan kegiatan eksternal sehingga waktu proses setup dapat dipersingkat.

Dengan penerapan metode SMED pengurangan waktu setup dengan merubah proses setup dari internal setup menjadi eksternal setup didapatkan pengurangan sebanyak 12 menit (19,67\%)

Untuk menunjang pelaksanaan perbaikan yang dilakukan secara terus menerus dan untuk mencegah banyaknya proses stop yang terjadi selama pengemasan primer tersebut, maka dilakukan brainstorming dengan para operator. Hasil dari proses brainstorming dibuat diagram fishbone untuk mengklasifikasi penyebab dan melakukan tindakan sesuai dari hasil temuan.

Pada Tabel 5 didapatkan usulan ataupun modifikasi yang harus dilakukan untuk memperbaiki proses setup juga untuk mencegah terulangnya small stop yang terjadi dalam proses pengemasan primer. Proses kemudian dilakukan untuk batch berikutnya dengan melakukan beberapa improvement, menghasilkan waktu setup total hanya 45 menit.

Table 4. Proses Setup Setelah Penerapan Proses SMED

\begin{tabular}{clccc}
\hline $\begin{array}{c}\text { Langkah } \\
\text { ke- }\end{array}$ & \multicolumn{1}{c}{ Proses } & $\begin{array}{c}\text { Internal } \\
\text { (menit) }\end{array}$ & $\begin{array}{c}\text { Eksternal } \\
\text { (menit) }\end{array}$ & Pelaksana \\
\hline 1 & Menyiapkan tools, p10, p5, ku L, T 10 & 0 & 2 & Asisten Op \\
2 & Memasang hopper bulk & 7 & 0 & Operator \\
3 & Mengisi bulk ke hopper bulk & 15 & 0 & Asisten Op \\
4 & Membuka dies pada rotary pan & 4 & 0 & Operator \\
5 & Memilih tube holder & 0 & 1 & Asisten Op \\
6 & Memasang tube holder & 5 & 0 & Operator \\
7 & Mengatur ketinggian filling rig & 5 & 0 & Operator \\
8 & Melakukan adjustment cramping & 10 & 0 & Operator \\
9 & Menyiapkan nomor batch & 0 & 3 & Asisten Op \\
10 & Memasang nomor batch pada stamp & 0 & 3 & Asisten Op \\
11 & Memasang stamp batch pada filling rig & 3 & 0 & Operator \\
12 & Melakukan pengaturan dosing pump & 0 & 3 & Operator \\
\hline
\end{tabular}

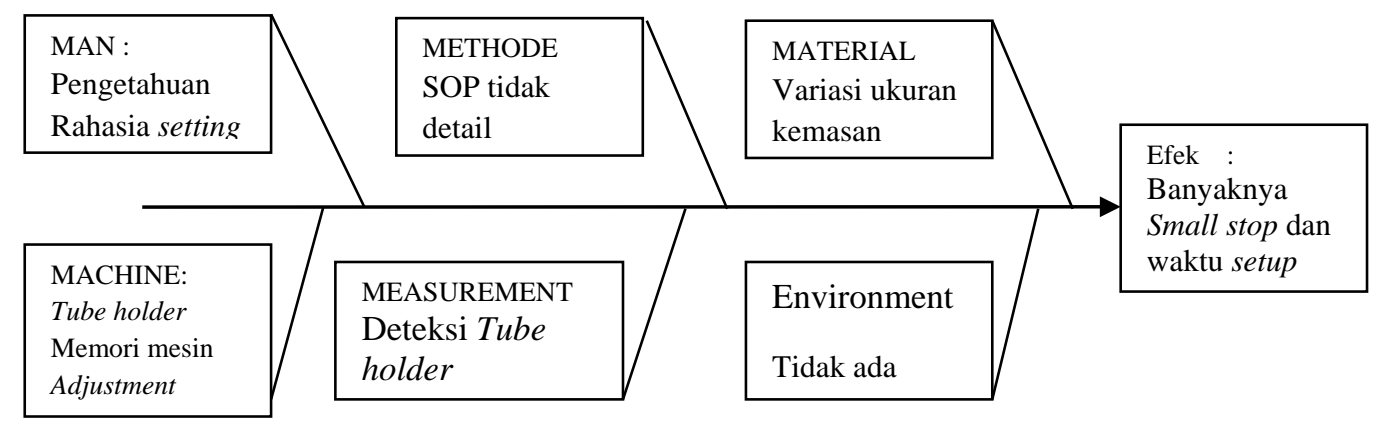

Gambar 2. Fishbone Diagram

Tabel 5. Rincian dan Solusi

\begin{tabular}{|c|c|c|c|}
\hline Klasifikasi & Penyebab & Rincian & Solusi \\
\hline \multirow{2}{*}{$M A N$} & Pengetahuan & $\begin{array}{l}\text { Pengetahuan tentang mesin diantara } \\
\text { operator tidak sama. }\end{array}$ & Menyamakan pengetahuan operator. \\
\hline & Rahasia & $\begin{array}{l}\text { Setiap orang mempunyai rahasia } \\
\text { sendiri dalam proses setting mesin. }\end{array}$ & Melakukan sharing mengenai proses \\
\hline
\end{tabular}


Lanjutan Tabel 6. Rincian dan Solusi (Lanjutan)

\begin{tabular}{|c|c|c|c|}
\hline Klasifikasi & Penyebab & Rincian & Solusi \\
\hline \multirow{3}{*}{ MACHINE } & Tube Holder & $\begin{array}{l}\text { Terdapat } 3 \text { set tube holder untuk } \\
\text { ukuran tube } 5 \text { gram dan } 10 \text { gram dan } \\
2 \text { set untuk tube } 15 \text { gram }\end{array}$ & $\begin{array}{l}\text { Melakukan seleksi dan menandai } \\
\text { Tube Holder yang bagus dan } \\
\text { menyingkirkan yang tidak di } \\
\text { gunakan. }\end{array}$ \\
\hline & Memori mesin & $\begin{array}{l}\text { Tidak adanya penanda mekanis } \\
\text { untuk proses set tinggi rig dan } \\
\text { cramping set }\end{array}$ & $\begin{array}{l}\text { Memberi tanda pada mesin agar } \\
\text { proses setting tidak memakan waktu } \\
\text { lama }\end{array}$ \\
\hline & Adjustment & $\begin{array}{l}\text { Mekanisme mikro adjustment bobot } \\
\text { isi tube sangat tergantung kepada } \\
\text { viskositas bulk krim }\end{array}$ & $\begin{array}{l}\text { Perlu adanya modifikasi mesin untuk } \\
\text { meningkatkan akurasi dan kestabilan } \\
\text { pengisian. }\end{array}$ \\
\hline \multirow{2}{*}{ METHODE } & $\begin{array}{l}\text { SOP tidak } \\
\text { detail }\end{array}$ & $\begin{array}{l}\text { SOP tidak secara rinci menjelaskan } \\
\text { prosedur setting. }\end{array}$ & $\begin{array}{l}\text { Melakukan perubahan SOP agar } \\
\text { lebih detail dan form khusus sebagai } \\
\text { panduan setting. }\end{array}$ \\
\hline & $\begin{array}{l}\text { Dokumentasi } \\
\text { stop }\end{array}$ & $\begin{array}{l}\text { Tidak ada dokumentasi small stop } \\
\text { selama proses, sehingga tidak } \\
\text { terdeteksi }\end{array}$ & $\begin{array}{l}\text { Membuat dokumentasi khusus untuk } \\
\text { small stops untuk mengidentifikasi } \\
\text { penyebabnya. }\end{array}$ \\
\hline \multirow[t]{2}{*}{ MEASUREMENT } & $\begin{array}{l}\text { Deteksi } \\
\text { tube holder }\end{array}$ & $\begin{array}{l}\text { Tidak ada alat untuk mendeteksi } \\
\text { tube holder yang sudah aus }\end{array}$ & $\begin{array}{l}\text { Membuat jadwal pemeriksaan untuk } \\
\text { tube holder dan secara berkala } \\
\text { melakukan pemisahan kepada tube } \\
\text { holder yang tidak memenuhi syarat } \\
\text { lagi. }\end{array}$ \\
\hline & $\begin{array}{l}\text { Deteksi setting } \\
\text { mesin }\end{array}$ & $\begin{array}{l}\text { Tidak ada alat untuk mendeteksi } \\
\text { kekurangan setting mesin sehingga } \\
\text { adjustment dilakukan setelah produk } \\
\text { keluar. }\end{array}$ & $\begin{array}{l}\text { Melakukan modifikasi mesin untuk } \\
\text { memudahkan proses setting mesin } \\
\text { dengan memberikan visual marker } \\
\text { pada mesin. }\end{array}$ \\
\hline MATERIAL & $\begin{array}{l}\text { Variasi } \\
\text { kemasan } \\
\text { primer }\end{array}$ & $\begin{array}{l}\text { Terdapat beberapa variasi dalam } \\
\text { ukuran tube aluminium yang berbeda } \\
\text { supplier }\end{array}$ & Menetapkan standar tube \\
\hline ENVIRONMENT & Tidak ada & Tidak ada & Tidak ada \\
\hline
\end{tabular}

Tabel 7. Proses Set Up Setelah Dilakukan Improvement

\begin{tabular}{clccc}
\hline $\begin{array}{c}\text { Langkah } \\
\text { ke- }\end{array}$ & \multicolumn{1}{c}{ Proses } & $\begin{array}{c}\text { Internal } \\
\text { (menit) }\end{array}$ & $\begin{array}{c}\text { Eksternal } \\
\text { (menit) }\end{array}$ & Pelaksana \\
\hline 1 & Menyiapkan tools, p10, p5, ku L, T 10 & 0 & 0 & - \\
2 & Memasang hopper bulk & 5 & 0 & Operator \\
3 & Mengisi bulk ke hopper bulk & 15 & 0 & Asisten Op \\
4 & Membuka dies pada rotary pan & 4 & 0 & Asisten Op \\
5 & Memilih tube holder & 0 & 0 & - \\
6 & Memasang tube holder pada pan rig & 5 & 0 & Operator \\
7 & Mengatur ketinggian filling rig & 3 & 0 & Operator \\
8 & Melakukan adjustment cramping & 5 & 0 & Operator \\
9 & Menyiapkan nomor batch & 1 & 1 & Asisten Op \\
10 & Memasang nomor batch pada stamp & 2 & 2 & Asisten Op \\
11 & Memasang stamp batch pada filling rig & 2 & 0 & Operator \\
12 & Melakukan pengaturan dosing pump & 3 & 0 & Operator \\
& Total & 45 & 3 & \\
\hline
\end{tabular}

Proses Improvement juga berhasil dilakukan setelah penerapan SMED dengan total small stop selama proses 6 jam terjadi sebanyak 6 kali. pada tahap ini terjadi penurunan waktu sebanyak 9 kali atau terjadi penurunan sebanyak $60 \%$
Sebelum penerapan SMED kegiatan setup yang dilakukan oleh satu operator pada satu mesin, mengakibatkan operator melakukan kegiatan setup pada saat mesin berhenti. Hal ini juga mengakibatkan waktu setup menjadi lebih lama. Karena operator harus melakukan sendiri 
Tabel 8. Small Stops Selama Proses Pengemasan Primer Setelah Proses Improvement

\begin{tabular}{cllcc}
\hline $\begin{array}{c}\text { Stop } \\
\text { ke - }\end{array}$ & \multicolumn{1}{c}{ Proses } & \multicolumn{1}{c}{ Penyebab } & $\begin{array}{c}\text { Waktu } \\
\text { (menit) }\end{array}$ & Pelaksana \\
\hline 1 & Melakukan pengaturan dosing pump & Bobot isi kurang & 1 & Operator \\
2 & Melakukan pengaturan dosing pump & Bobot isi kurang & 1 & Operator \\
3 & Mengisi bulk ke hopper bulk & Bulk lot ke dua & 15 & Asisten Op \\
4 & Change over & Ganti kemasan primer & 25 & Operator \\
5 & Melakukan adjustment cramping & Lipatan cramping & 5 & Operator \\
6 & Melakukan pengaturan dosing pump & Bobot isi kurang & 1 & Operator \\
\hline & Total & & 48 & \\
\hline
\end{tabular}

kegiatan setup dalam satu mesin dan kegiatan tersebut dilakukan secara internal setup. Setelah penerapan SMED, kegiatan setup dalam proses pengemasan primer dilakukan oleh operator dan asisten. Asisten membantu operator melakukan kegiatan setup pada saat mesin berjalan. Asisten hanya membantu kegiatan setup saat mesin berjalan, jadi setelah satu mesin selesai asisten bisa membantu pada mesin yang lain atau tahap berikutnya. Persiapan part, tools dan aktifitas perawatan tidak dilakukan ketika mesin dalam keadaan berhenti [9], aktivitas ini mengkonversi aktivitas internal setup menjadi eksternal setup [10]. Selanjutnya penyederhanaan penggantian peralatan, yaitu menghilangkan aktivitas mengambil peralatan. Penyederhanaan kedua adalah pada penyesuaian tools, yaitu menghilangkan aktivitas penyesuaian pada peralatan. Kemudian menerapkan operasi paralel yaitu dengan menggunakan 2 operator.

Kendala yang dihadapi dalam proses produksi di pabrik terutama ditahap pengemasan primer produk adalah:

Faktor Manusia yaitu pengetahuan dan rahasia setting, pengetahuan dalam hal proses operasional mesin dan setup sangat terpisah jauh diantara operator, baik diantara operator junior maupun senior, hampir tiap orang mempunyai cara atau metoda khusus sebagai referensi dalam melakukan setup. Hal ini bisa diketahui dari proses brainstorming diantara operator yang menjalankan mesin ini. Informasi yang didapat pada tahap ini di gunakan untuk memperbaiki SOP agar lebih detail.

Faktor mesin. Terdapat beberapa set tube holder dari supplier yang berbeda dan dengan bahan baku yang berbeda yaitu Teflon dan Aluminium yang mempunyai karateristik berbeda. Tube ini tidak diberi tanda yang membedakan antara set yang satu dan yang lain. Pada tahap ini dilakukan seleksi menggunakan jangka sorong dan sampel tube aluminium dan hanya tube holder yang memenuhi syarat yang digunakan kembali. Dari total 3 set (@16 tube holder) hanya sekitar 20 buah yang masih masuk spesifikasi. Tube holder ini kemudian diletakkan dalam tempat khusus dengan penomoran untuk menghilangkan proses pemilihan tube holder pada proses setup. Hal ini juga ternyata menghilangkan proses small stop karena faktor variasi ukuran tube holder bisa dihilangkan. Kemudian dalam melakukan setup mesin pada bagian filling rig. proses setup jauhnya lengan cramping juga tingginya filling rig diberikan penanda pada bagian mesin.

Faktor Metode. SOP diubah menurut hasil sharing tentang operasional dan setting mesin. dan dijelaskan lebih detail. Kemudian dibuat suatu SOP untuk mendokumentasi terhentinya proses untuk memberikan masukan kepada departemen engineering dalam proses improvement mesin.

Faktor Measurement. Banyaknya waktu stop dan lamanya waktu setup diakibatkan adalah ketiadaan mekanisme untuk melakukan pengukuran di tempat proses. Baik pengukuran dimensi tube holder yang ternyata banyak yang telah aus, juga ukuran dalam proses setting mesin terutama filling rig yaitu mekanisme cramping dan dosing pump-nya.

Faktor Material. Bahan baku pengemas dalam proses ini juga banyak mempunyai variasi baik dimensinya ataupun permukaaannya. Hal ini hanya bisa diperbaiki dengan menetapkan standar tube sehingga dimensi tube holder dapat mengikuti standar ukuran tube ini dengan benar. 


\section{KESIMPULAN}

Pada penelitian ini penerapan SMED dalam proses pengemasan primer produk bulk krim menggunakan mesin filling krim di gunakan bersama metode lain sehingga pada langkah 1 dan 5 bisa dihilangkan dengan penerapan 5S. Kemudian penerapan standarisasi proses small stop untuk melakukan penggantian holder bisa dihindari sehingga menghemat waktu setup sebanyak 16 menit Dengan menerapkan SMED pada pengemasan primer bisa menghemat waktu setup dari 61 menit/batch menjadi 49 menit/batch. Penerapan SMED dilakukan dengan cara menambah satu asisten untuk melayani semua setup eksternal. Penerapan 5 S dan Standarisasi Prosedur juga sangat membantu dalam proses pengurangan waktu setup dan penurunan banyaknya small stop selama proses. Sehingga total pengurangan waktu setup yang dicapai adalah 16 menit (26,23\%) dan total penurunan waktu small stop sebesar $60 \%$

\section{DAFTAR PUSTAKA}

[1] Pine, J., Victor, B., \& Boynton, A. C. (1993). Making Mass Costumization Work.

[2] Dave, Y., \& Sohani, N. (2012). Single Minute Exchange of Dies: A literature Review. Konya Teknokent.

[3] Raikar, N. A. (2015). Reduction in Setup Time by SMED Methodology: A Case Study. International Journal of Latest Trends in Engineering and Technology (IJLTET), Vol. 5 Issue 4 .

[4] Marchwinski, C., \& Shook, J. (2003). Lean Lexicon : A graphical glossary for lean thinkers. Brookline: MA: Lean Enterprise Institute.

[5] Zandin, K. B. (Ed.). (2004). Maynards Industrial Engineering Handbook (Vol. 5th ed). McGraw Hill.

[6] Shingo, S. (1981). Study of Toyota Production System. (A. P. Dillon, Trans.) Productivity Press.

[7] Shingo, S. (1985). A Revolution in Manufacturing.The SMED System. Cambridge Connecticut: Productivity Press USA.

[8] Suhardi, B., \& Satwikaningrum, D. (2015). Perbaikan Waktu Set Up dengan menggunakan Metoda SMED. Seminar Nasional IENACO.

[9] Sivasankar, M., Dhandapani, N., Manojkumar, S., Karthick, N., Raja, K., \& Yuvaraj, J. (2011). Experimental verification of Single Minute Exchange Dies (SMED). Recent Research in Science and Technology, 3(3); 92-97 .

[10] Tanzil, R. N., Damayanti, D. D., \& Suryadhini, P. P. (2015). Usulan Perbaikan Waktu Setup dalam Meminimasi Keterlambatan Penyelesaian Order pada Komponen Isolating Cock dengan Metode SMED di PT. Pindad (Persero). e-Proceeding of Engineering, Vol.2, No.2 | Page 3981. 